\title{
PRODUÇÃO DE MUDAS DE Anadenanthera macrocarpa EM FUNÇÃO DE SUBSTRATOS ALTERNATIVOS E DA FREQUÊNCIA DE FERTIRRIGAÇÃO
}

\author{
Marcelo Bortoli Uliana ${ }^{1}$, Rubens $\mathrm{Fey}^{2}$, Marlene Matos Malavasi ${ }^{3}$, Ubirajara Contro Malavasi ${ }^{4}$ \\ ${ }^{1}$ Eng. Agrônomo, M.Sc., UNIOESTE, Marechal Cândido Rondon, PR, Brasil - marcelo.uliana@yahoo.com.br \\ ${ }^{2}$ Eng. Agrônomo, Dr., UFFS, Laranjeiras do Sul, PR, Brasil - rubens.fey@uffs.edu.br \\ ${ }^{3}$ Eng $^{\mathrm{a}}$ Agrônoma, Dra ., UNIOESTE, Marechal Cândido Rondon, PR, Brasil - marlenemalavasi@yahoo.com.br \\ ${ }^{4}$ Eng. Florestal, Dr., UNIOESTE, Marechal Cândido Rondon, PR, Brasil - biramalavasi@yahoo.com.br
}

Recebido para publicação: 08/04/2013 - Aceito para publicação: 10/01/2014

\begin{abstract}
Resumo
Com o aumento da demanda de produtos da cana-de-açúcar, seu resíduo (bagaço), que possui baixo custo nas regiões produtoras e potencial de uso para produção de mudas, pode ser uma alternativa viável. Este ensaio objetivou quantificar o crescimento de mudas de angico-vermelho em função de substratos à base de bagaço de cana-de-açúcar decomposto e com diferentes intervalos de fertirrigação. O ensaio foi conduzido em um delineamento de blocos ao acaso e testou três frequências de fertirrigação ( 7,14 e 21 dias), mais a testemunha (sem fertirrigação), e três substratos à base de bagaço de cana-de-açúcar decomposto com a adição de húmus, vermiculita, vermiculita e areia, e um substrato comercial isento de bagaço de cana (testemunha). As mensurações das mudas incluíram: altura, diâmetro do coleto, massa seca dos tecidos aéreos e radiculares aos 50, 80, 110 e 140 dias após a emergência. Os resultados indicaram maior desenvolvimento de mudas de angicovermelho com o substrato bagaço de cana decomposto misturado com húmus na proporção 7:3 (v/v), enquanto as frequências de fertirrigação testadas pouco influenciaram o crescimento durante os períodos de avaliação.

Palavras-chave: Viveiros florestais; morfometria de mudas; qualidade de mudas.
\end{abstract}

\begin{abstract}
Seedling production of Anadenanthera macrocarpa as a function of substrates and fertigation regimes. This essay evaluated the development of seedlings of Anadenanthera macrocarpa as a function of substrates made from decomposed sugarcane and fertigation frequency. The essay was conducted in a randomized block design with three fertigation frequencies $(7,14$ or 21 days) plus a control (without fertigation) and three substrates from decomposed sugarcane mixed with humus, vermiculite, vermiculite and sand, and a commercial substrate (control). Measurements included seedling height, stem diameter, and shoot and root biomass at 50, 80, 110, and 140 days after seed emergence. The results revealed faster growth of Anadenanthera macrocarpa seedlings produced with decomposed sugarcane mixed with humus 7:3 (v/v), while fertigation frequency had little effect upon seedling growth.

Keywords: Forest nurseries; seedling morphometry; seedling quality.
\end{abstract}

\section{INTRODUÇÃO}

Anadenanthera macrocarpa (Benth.) Brenan é uma espécie decídua lenhosa, pioneira e de desenvolvimento rápido (5-6 m em dois anos), segundo Lorenzi (2008) e Gonçalves et al. (2005). Gonçalves et al. (2012) reportaram que o nitrogênio e o fósforo são os nutrientes que mais limitam o crescimento das mudas da espécie.

Na produção de mudas florestais, a escolha do substrato e da frequência no fornecimento de nutrientes são aspectos importantes para formação de mudas com qualidade, por razões ecológicas (sobrevivência a campo) e econômicas (NAVARRO et al., 2006). 
Entre os materiais utilizados como substrato na produção de mudas, encontram-se a casca de arroz carbonizada (LUCAS et al., 2002), o esterco bovino curtido (CAVALCANTI et al., 2002), o composto orgânico (TRINDADE et al., 2001), a casca de acácia-negra (SOUZA et al., 2003) e o húmus de minhoca (LIMA et al., 2001).

A escolha do substrato deve considerar a disponibilidade de materiais ou resíduos, assim como suas características físicas e custo. A disponibilidade de nutrientes no substrato também é um fator a ser levado em consideração, e havendo deficiência, estes devem ser disponibilizados às mudas. No caso de mudas de angico-vermelho, Gonçalves et al. (2012) reportaram que o nitrogênio e o fósforo são os nutrientes que mais limitam o crescimento.

Portanto, a utilização de substratos alternativos e de fácil aquisição depende da disponibilidade daqueles resíduos. O bagaço de cana-de-açúcar pode ser uma opção (MELO et al., 2003), pois é um subproduto que pode ser encontrado na maioria das regiões brasileiras.

Nesse contexto, este trabalho objetivou avaliar a viabilidade técnica do uso de substratos à base de bagaço de cana decomposto e em função da frequência de fertirrigação na produção de mudas de A. macrocarpa.

\section{MATERIAL E MÉTODOS}

O experimento foi conduzido durante 2007 e 2008, em instalações com coordenadas geográficas

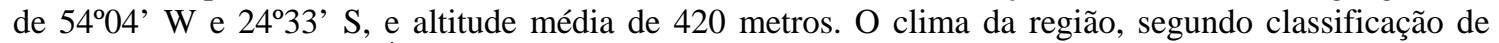
Köppen, é o Subtropical Úmido Mesotérmico (Cfa), com verões quentes (temperatura média superior a $22{ }^{\circ} \mathrm{C}$ ), invernos com geadas pouco frequentes (temperatura média inferior a $18{ }^{\circ} \mathrm{C}$ ) e precipitação média anual de $1.500 \mathrm{~mm}$.

Sementes de A. macrocarpa foram obtidas de frutos maduros coletados em fragmentos florestais na região. Para a produção de mudas, utilizou-se a semeadura direta de quatro sementes à temperatura ambiente em tubetes de polietileno preto de $120 \mathrm{~cm}^{3}$ e oito estrias. Não foi realizado nenhum tipo de tratamento para quebra de dormência das sementes (MEDEIROS, 2001). Os tubetes foram dispostos em bandejas de polipropileno com 96 células, sobre bancadas de madeira a 0,3 m do solo, em ambiente semissombreado (50\% de sombreamento), conforme descreve Lorenzi (2008). Após a emergência das sementes, efetuou-se o raleamento, deixando uma plântula por tubete.

Os substratos à base de bagaço de cana-de-açúcar decomposto (BCD) foram formados com a adição de húmus comercial $(\mathrm{BCD}+\mathrm{H})$, na proporção de 7:3 (v/v); de vermiculita e areia (BCD+V+A), na proporção de 7:2:1 (v/v/v); de vermiculita (BCD+V), na proporção de 7:3 (v/v); e um substrato comercial à base de casca de pinus (Tabela 1). A frequência da fertirrigação empregou ciclos a cada 7, 14 e 21 dias após a emergência das sementes, mais o tratamento-controle (sem fertirrigação).

O BCD, resultante da trituração de bagaço de cana-de-açúcar em moinho industrial, para uniformização das partículas, foi disposto em leiras de $2 \mathrm{~m}$ de comprimento por $80 \mathrm{~cm}$ de largura. Cada camada de bagaço de cana-de-açúcar de $10 \mathrm{~cm}$ de espessura recebeu uma solução de água contendo 5\% de nitrogênio, para reduzir a relação $\mathrm{C} / \mathrm{N}$ e acelerar o processo de decomposição. As leiras foram umedecidas uma vez por mês, permanecendo em ambiente arejado e ventilado por 90 dias.

As mudas foram irrigadas diariamente com água via microaspersão, utilizando-se motobomba com pressão de trabalho de 15 psi. A lâmina de água aplicada foi definida pela aplicação de 27 litros de água em mil tubetes, momento em que ocorreu a percolação de água. A mesma lâmina de água foi utilizada do início ao término da condução do ensaio. O tempo de funcionamento das irrigações diárias foi de 25 minutos com água e de 15 minutos com a aplicação da fertirrigação a cada 7, 14 e 21 dias após a emergência das sementes.

A fertirrigação foi composta da fórmula 13-06-40, correspondente a 2,5 g.L $L^{-1}$ de N, 0,5 g. $L^{-1}$ de $\mathrm{P}_{2} \mathrm{O}_{5}$ e 2 g. $\mathrm{L}^{-1}$ de $\mathrm{K}_{2} \mathrm{O}$. As fontes de micronutrientes utilizadas foram sulfato de cobre e zinco, ácido bórico e permanganato de cálcio e magnésio. Essas doses foram baseadas nas recomendações de Higashi et al. (2002) para o eucalipto, e foram aproveitadas neste trabalho pela ausência de recomendação específica. A condutividade elétrica da solução foi mantida abaixo de 3,6 mS.cm ${ }^{-2}$, como sugerido por Sarzi et al. (2010).

A avaliação morfométrica das mudas incluiu a altura (H), o diâmetro do coleto (DC), a massa da matéria seca da parte aérea (MSPA) e da raiz (MSR) e a relação MSPA/MSR. As massas secas foram 
obtidas pelo método de secagem em estufa de circulação forçada de ar a $65{ }^{\circ} \mathrm{C} \pm 2{ }^{\circ} \mathrm{C}$, até massa constante de cinco plantas por repetição, aleatoriamente selecionadas. As mensurações foram realizadas em intervalos de 30 dias, a partir do quinquagésimo dia após emergência (DAE) até os 140 DAE, totalizando quatro avaliações. Como parâmetro de escolha do tempo, em outro trabalho com angico-vermelho, GONÇALVES et al. (2012) observaram que, entre 100 e 120 DAE, foram suficientes para obter plântulas com altura superior a $25 \mathrm{~cm}$ e $4 \mathrm{~mm}$ de diâmetro.

O experimento seguiu um delineamento experimental em blocos ao acaso, em arranjo de parcelas subdivididas, com quatro repetições, sendo estabelecidos como tratamentos as frequências de fertirrigação na parcela (0, 7, 14 e 21 dias) e os substratos nas subparcelas (comercial, BCD+H, $\mathrm{BCD}+\mathrm{V}+\mathrm{A}$ e $\mathrm{BCD}+\mathrm{V})$, com 4 repetições de 48 mudas cada.

Os dados de cada avaliação foram submetidos à análise de variância pelo teste Fisher. Quando da existência de diferenças, as médias foram comparadas pelo teste Tukey a 5\% de probabilidade.

Tabela 1. Características físico-químicas ${ }^{1}$ dos substratos utilizados na produção de mudas de A. macrocarpa.

Table 1. Physical-chemical characteristics of substrates used for production of A. macrocarpa seedlings.

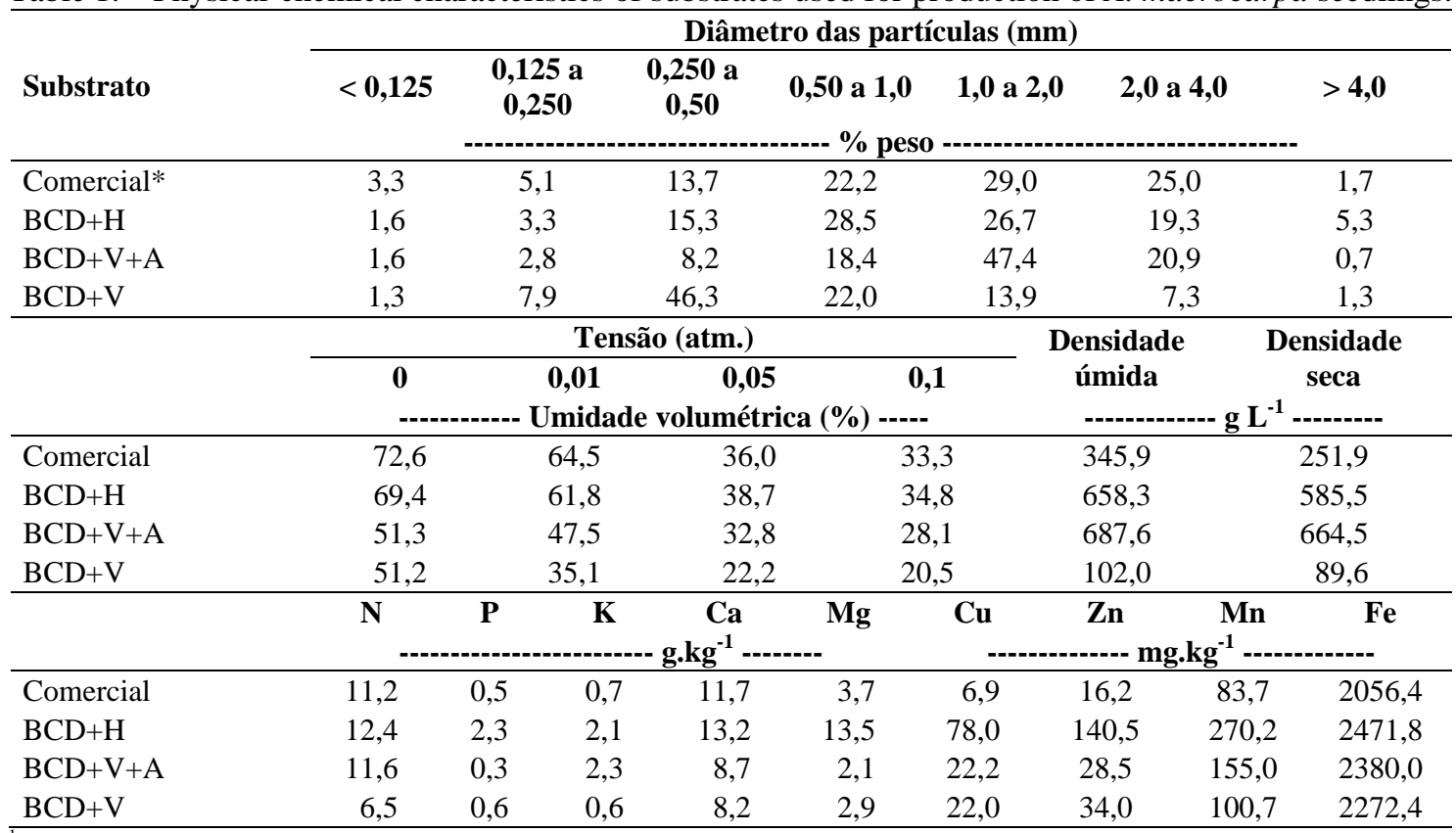

${ }^{1}$ Resultados obtidos através de análise realizada no Laboratório de Solos e Adubos FCAV/UNESP, Jaboticabal, SP. *Comercial: Plantmax ${ }^{\circledR} \mathrm{HA}$; BCD +H: mistura de bagaço de cana decomposto e húmus comercial 7:3; BCD+V+A: mistura de bagaço de cana decomposto, vermiculita e areia 7:2:1; BCD+V: bagaço de cana decomposto e vermiculita 7:3.

\section{RESULTADOS}

Não houve interação $(p>0,05)$ entre as frequências de fertirrigação e os substratos utilizados na medida da altura, diâmetro do caule, massa seca de raiz e parte aérea em mudas de $A$. macrocarpa até os $140 \mathrm{DAE}$

O composto de bagaço de cana-de-açúcar acrescido de húmus (BCD+H) resultou no maior crescimento em altura $(26,06 \mathrm{~cm})$ das mudas de angico-vermelho até 140 DAE (Figura 1A), com um crescimento médio de 3,3 cm a cada mês. Em contrapartida, o substrato comercial e o bagaço de cana com vermiculita (BCD+V) resultaram em plantas com média de 11,25 cm de altura aos 140 DAE.

A frequência em fornecer nutrientes não diferenciou o crescimento em altura das mudas até os 80 DAE (Figura 1B). A avaliação realizada aos 110 DAE mostrou existir uma maior demanda nutricional pelas mudas de angico para o crescimento em altura das mudas. Nesse período, as fertilizações a cada 7 dias resultaram em mudas com 16,37 cm de altura, independentemente dos substratos utilizados. 


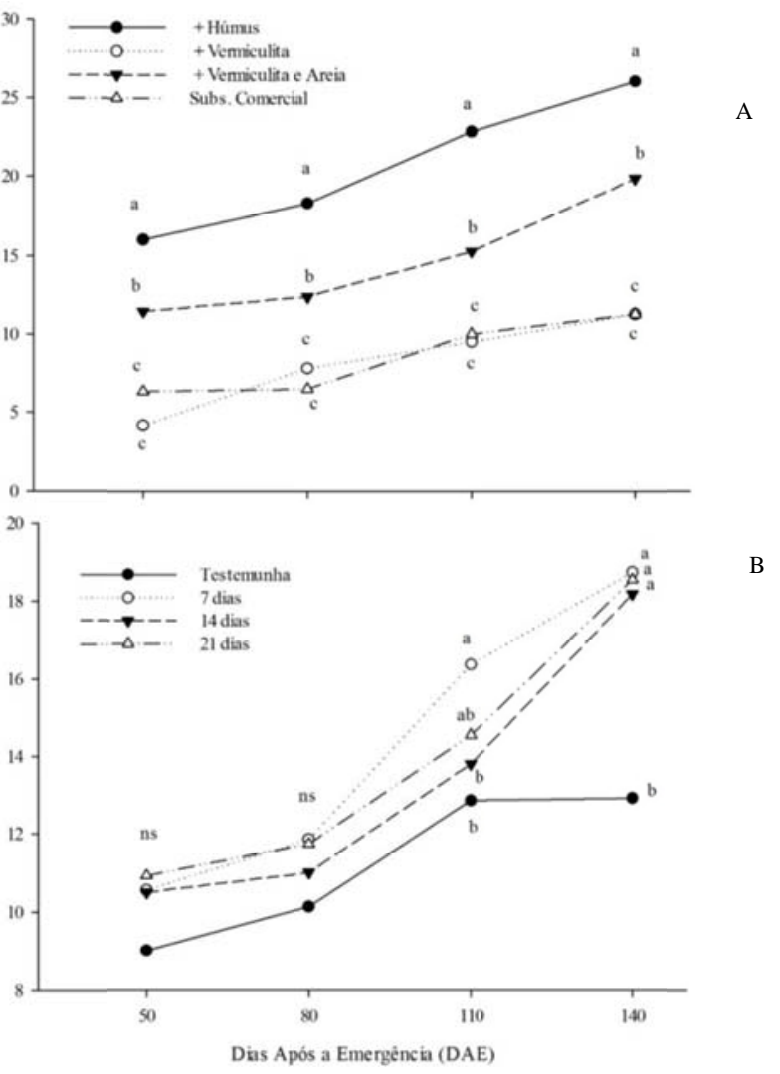

*Letras minúsculas iguais indicam que não há diferença ao nível de 5\% pelo teste de Tukey entre os tratamentors no mesmo período (DAE) de avaliação, enquanto "ns" indica que não foi possível a visualização estatística das diferenças.

Figura 1. Crescimento em altura de Anadenanthera macrocarpa em substratos à base de cana-de-açúcar decomposto acrescido de diferentes misturas (húmus, vermiculita e vermiculita com areia) e substrato comercial (A), e sob diferentes intervalos (7, 14 e 21 dias) entre fertirrigações (B).

Figure 1. Height growth of Anadenanthera macrocarpa on based of substrates decomposed sugarcane supplemented with different mixtures (humus, vermiculite, vermiculite and sand), and commercial substrate (A), and under different intervals (7, 14 and 21 days) between fertigation (B).

Não houve efeito das frequências de fertirrigação no diâmetro do caule em mudas de angicovermelho até os 140 DAE. O substrato com BCD mais vermiculita e o substrato comercial externaram menores valores do diâmetro em todos os substratos avaliados (Figura 2). Mudas produzidas em substrato BCD+H resultaram em maior diâmetro do coleto que os demais substratos testados, com valor de 2,03 mm na avaliação aos 140 DAE (Figura 2).

Mudas de angico-vermelho não apresentaram diferenças na massa seca de raiz em função da frequência de fertirrigação. Com relação ao efeito dos substratos, mudas produzidas com BCD+H externaram os maiores valores da massa seca aérea e radicular em todas as avaliações, seguidas daquelas com BCD+V+A, BCD+V e do substrato comercial (Figuras 3A e B).

A tendência resultante dos valores plotados na figura 3B corrobora a afirmação acima, de que o crescimento avaliado até os 110 DAE indicou uma fase de incremento dos tecidos aéreos, seguida do rápido ganho em massa seca radicular avaliada aos $140 \mathrm{DAE}$.

A relação MSPA/MSR calculada em mudas de angico-vermelho aos 110 DAE resultou em valor elevado (Figura 4), resultante da priorização do crescimento aéreo, enquanto que os menores valores aos 140 DAE decorrem da maior alocação à massa seca radicular (Figuras 3A e 3B).

Aos 140 DAE, o substrato BCD+H resultou em mudas de angico-vermelho com a maior razão MSPA/MSR do que em mudas conduzidas com os demais substratos. 


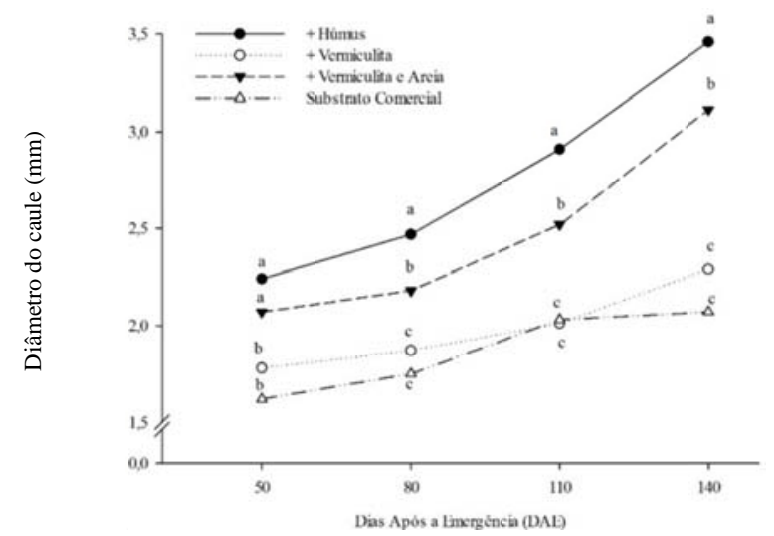

*Letras minúsculas iguais indicam que não há diferença ao nível de 5\% pelo teste de Tukey entre os tratamentos no mesmo período (DAE) de avaliação, enquanto "ns" indica que não foi possível a visualização estatística das diferenças.

Figura 2. Diâmetro do coleto em mudas de A. macrocarpa em função dos substratos à base de bagaço de cana-de-açúcar e da frequência de fertirrigações entre 50 e 140 DAE.

Figure 2. Growth in diameter of $A$. macrocarpa seedlings in different substrates icomposed of sugarcane bagasse and average fertigation frequencies between 50 and 140 DAE.

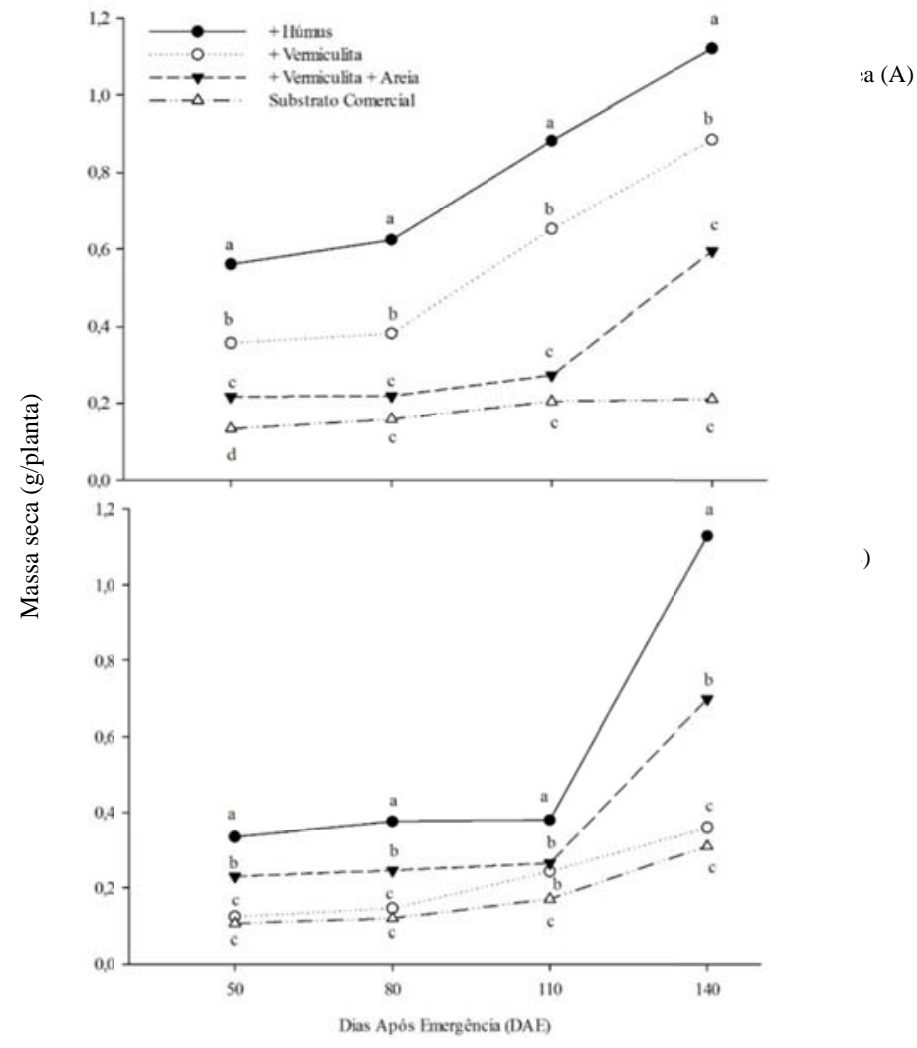

Médias seguidas por mesma letra dentro de cada DAE não diferem estatisticamente pelo teste de Tukey a 5\% de probabilidade.

Figura 3. Crescimento em massa seca da parte aérea (A) e crescimento em massa seca da raiz (B) de Anadenanthera macrocarpa em diferentes substratos à base de bagaço de cana-de-açúcar decomposto e na média de frequências de fertirrigações entre 50 e 140 DAE.

Figure 3. Growth in dry mass of air part (A) and growth in dry mass root (B) of Anadenanthera macrocarpa in different substrates composed of sugar cane bagasse and decomposed average fertigation frequencies between 50 and 140 DAE. 


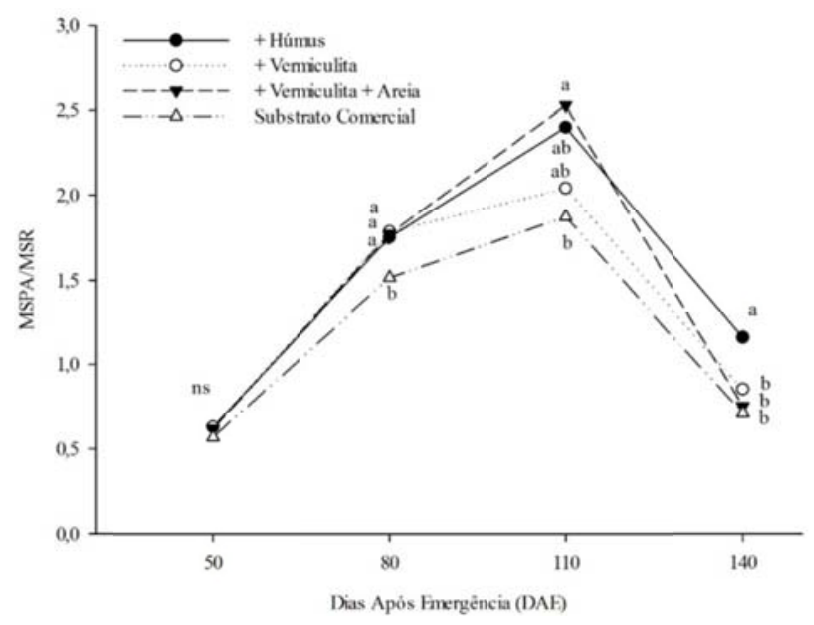

Médias seguidas por mesma letra dentro de cada DAE não diferem estatisticamente pelo teste de Tukey a 5\% de probabilidade.

Figura 4. Relação massa seca da parte aérea/massa seca da raiz (MSPA/MSR) de Anadenanthera macrocarpa em diferentes substratos à base de bagaço de cana decomposto e na média de frequências de fertirrigações entre 50 e 140 DAE.

Figure 4. Value shoot/root dry mass of different Anadenanthera macrocarpa based on substrates of decomposed bagasse and average fertigation frequencies between 50 and 140 DAE.

\section{DISCUSSÃO}

A composição químico-física dos substratos testados apresentou diferenças. Para Minami e Puchala (2000), as características físicas e químicas do substrato devem oferecer as mellhores condições para o desenvolvimento das mudas. No presente ensaio, o substrato constituído de bagaço de cana mais húmus comercial $(\mathrm{BCD}+\mathrm{H})$ resultou em contínuo crescimento em altura, diâmetro e massa dos tecidos aéreos e radiculares (Figuras 1, 2 e 3).

As propriedades físicas dos substratos possivelmente não causaram diferenças nos resultados devido à boa drenagem e a irrigação diária (Tabela 1). Como o angico-vermelho foi plantado em tubetes de $120 \mathrm{~cm}^{3}$, a maior densidade dos substratos não prejudicou as plantas, por ter facilitado o contado das raízes com o substrato.

A composição química dos substratos pode ter influenciado nos resultados em função da grande variação (Tabela 1). Os maiores valores das variáveis morfométricas quantificadas em mudas conduzidas com o substrato BCD+H pode ser justificada pela maior concentração de fósforo naquele substrato, com teores que variaram entre 3,7 e 8,5 vezes superiores aos demais substratos (Tabela 1). O fósforo possui função central em reações de armazenamento e liberação de energia (TAIZ; ZEIGLER, 2009). Fey et al. (2010) observaram, em maracujá, que o fornecimento adequado de P às mudas proporciona ganhos tanto em nível radicular como da parte aérea. Gonçalves et al. (2012) trabalharam com angico-vermelho e observaram que os nutrientes que mais limitam o crescimento das mudas são o nitrogênio e o fósforo.

Gomes e Paiva (2004) também concluíram que um adequado suprimento de fósforo é importante no início do crescimento da planta para a formação dos primórdios vegetativos, uma vez que as raízes de plantas jovens absorvem fosfato muito mais rapidamente que as raízes de plantas mais velhas. A adição de húmus ao substrato resultou em benefícios, como o fornecimento de macro e micronutrientes também para outros autores, como Alves e Passoni (1997), ao cultivarem mudas de oiti (Licania tomentosa Benth.), que atingiram as maiores médias em altura quando cultivadas em substrato acrescido de composto orgânico e de vermicomposto.

Além de maior valor, o fornecimento de nutrientes às plantas via húmus pode resultar em maior disponibilidade (mineralizados), quando comparado aos outros substratos. Lima et al. (2006) também observaram que o húmus proporcionou os maiores teores de macronutrientes na produção de mudas de acerola (Malpighia emarginata DC.). Além disso, o húmus possui sabidamente maior CTC (capacidade de troca de cátions) que a vermiculita (LOPES; GUILHERME, 1989), o que possivelmente aumentou a 
disponibilidade dos demais nutrientes requeridos pelo angico-vermelho, e consequentemente favoreceu as mudas cultivadas em substrato com húmus.

Gonçalves et al. (2012) observaram que a absorção de nutrientes pelo angico é maior em solo/substrato com maior disponibilidade nutricional. Como, na tabela 1, o nitrogênio apresenta-se com teores semelhantes entre os substratos, atribui-se ao fósforo o maior crescimento ao substrato $\mathrm{BCD}+\mathrm{H}$ (Figuras 1, 2 e 3). Schumacher et al. (2004) também observaram relação entre a disponibilidade de fósforo no substrato e o crescimento em altura, diâmetro e massa seca de angico-vermelho.

Atributos morfométricos de mudas, como o diâmetro do colo e a altura da parte aérea, têm sido constantemente relacionados como indicadores de sobrevivência e potencial de crescimento pós-plantio (MASON, 2001). Neste estudo, mudas de angico-vermelho produzidas com BCD+H resultaram em maior altura (Figura 1). Navarro et al. (2006), ao analisaram 30 casos em que foi relacionada altura das mudas com a porcentagem de sobrevivência em campo, descreveram que em $36 \%$ dos casos existe uma relação positiva, ou seja, quanto maior a muda, maiores são as chances de sobrevivência em campo. Em contrapartida, a relação negativa foi descrita em apenas $9 \%$ dos casos, e em $55 \%$ a altura não influenciou a sobrevivência.

Neste trabalho, a mistura do substrato à base de bagaço de cana decomposto mais húmus resultou em mudas com maior diâmetro do caule (Figura 2). Conforme Gomes e Silva (2004), o diâmetro de colo é facilmente mensurável, sendo considerado por muitos pesquisadores como um dos mais importantes parâmetros para estimar a sobrevivência em campo de mudas de espécies lenhosas.

A relação MSPA/MSR representa um critério eficiente para a aferição da qualidade de mudas, pois indica a estratégia de alocação do carbono estrutural entre o sistema fotossintético e o de absorção de água e nutrientes. Mudas com uma alta relação com balanço desfavorável entre o sistema radicular e a parte aérea possuem menor chance de sobreviver quando plantadas em condições de estresse hídrico. Navarro et al. (2006) encontraram relação negativa neste parâmetro, ou seja, quanto maior a relação, menor a sobrevivência em campo.

No presente ensaio, foi calculada ampla variação da relação MSPA/MSR dos 80 aos 140 DAE, em razão do crescimento preferencial em altura (Figura 3A) até os 110 DAE e diminuição aos 140 dias, em face de ênfase do crescimento radicular (Figura 3B). Existe a necessidade de trabalhos que possibilitem referenciar esses índices com a sobrevivência no campo. Kozlowski (1966) defendeu que programas de fertilização não devem objetivar a produção de mudas com desenvolvimento que priorize o crescimento dos tecidos aéreos sem o correspondente crescimento radicular, por apresentarem baixa qualidade fisiológica em termos de sobrevivência pós-plantio.

De modo geral, a adição de nutrientes às plantas via fertirrigação causou pouco efeito nos aspectos morfométricos avaliados. No entanto, houve uma tendência de a frequência de 14 dias resultar em mudas maiores. Com relação à altura das plantas, os resultados indicaram que a fertirrigação acelerou o crescimento das mudas de angico-vermelho.

\section{CONCLUSÃO}

- O substrato formado pela mistura de bagaço de cana decomposto com húmus na proporção de 7:3 (v/v) pode ser utilizado como substrato alternativo para a produção de mudas de A. macrocarpa. Esse substrato possibilita maior crescimento em altura, diâmetro do caule e massa seca de raiz, em comparação aos substratos à base de bagaço de cana decomposto com areia, bagaço de cana decomposto com areia + vermiculita e substrato comercial.

- Nas condições avaliadas, intervalos de fertirrigação entre 7 e 21 dias não resultam em aumento no crescimento de mudas de angico-vermelho.

\section{REFERÊNCIAS}

ALVES, W. L.; PASSONI, A. A. Composto e vermicomposto de lixo urbano na produção de mudas de oiti (Licania tomentosa Benth.) para arborização. Pesquisa Agropecuária Brasileira, Brasília, v. 32, n. 10, p. 58 - 62, 1997. 
CAVALCANTI, N. B.; RESENDE, G. M.; BRITO, L. T. L. Emergência e crescimento do imbuzeiro (Spondias tuberosa) em diferentes substratos. Revista Ceres, Viçosa, v. 49, n. 282, p. 97 - 108, 2002.

FEY, R.; ZOZ, T.; STEINER, F.; CASTAGNARA, D. D.; FERREIRA, G. Crescimento inicial de mudas de maracujazeiro amarelo em função de doses crescentes de superfosfato simples. Revista Brasileira de Ciências Agrárias, Recife, v. 5, n. 3, p. 347 - 353, 2010.

GOMES, J. M.; PAIVA, H. N. Viveiro florestais: propagação sexuada. Viçosa: UFV. 2004. 116 p.

GOMES, J. M.; SILVA, A. R. Os substratos e sua influência na qualidade de mudas. In: BARBOSA, J. G.; MARTINEZ, H. E. P.; PEDROSA, M. W.; SEDIYAMA, M. A. N. Nutrição e adubação de plantas cultivadas em substratos. Viçosa: UFV: 2004. p. 190 - 225.

GOMES, K. C. O.; PAIVA, H. N.; NEVES, J. D. L.; BARROS, N. F.; SILVA, S. R. Influência da saturação por bases e do fósforo no crescimento de mudas de angico-branco. Revista Árvore, Viçosa, v. 28, n. 6, p. 785 - 792, 2004.

GONÇALVES, E. O.; PAIVA, H. N.; NEVES, J. C. L.; GOMES, J. M. Nutrição de mudas de angicovermelho (Anadenanthera macrocarpa (Benth.) Brenan) submetidas a doses de N, P, K, Ca e Mg. Revista Árvore, Viçosa, v. 36, n. 2, p. 219 - 228, 2012.

GONÇALVES, R. M. G.; GIANNOTTI, E.; GIANNOTTI, J. G.; SILVA, A. A. Aplicação de modelo de revegetação em áreas degradadas, visando a restauração ecológica da macrobacia do córrego da fazenda Itaqui, município de Gertrudes, SP. Revista Instituto Florestal, São Paulo, v. 17, n. 1, p. 73 - 95, 2005.

HIGASHI, E. A.; SILVEIRA, R. L. V. A.; GONSALVES, N. A. Nutrição e adubação em minijardim clonal hidropônico de Eucalyptus. CIRCULAR TECNICA IPEF, n. 194. 2002.

KOZLOWSKI, T. T. Physiological quality and mineral nutrition: physiological implications in afforestation. In: Word Forest Congress.6. 1966, Madrid. Proceedings of the Sixth Word Forest Congress. Madrid, 1966, p. 1304 - 1315.

LIMA, R. L. S.; FERNANDEZ, V. L. B.; OLIVEIRA, V. H.; HERNANDEZ, F. F. F. Crescimento de mudas de cajueiro-anão precoce CCP-76 submetidas a adubação orgânica e mineral. Revista Brasileira de Fruticultura, Jaboticabal, v. 23, n. 2, p. 391 - 395, 2001.

LIMA, R. L. S.; SIQUEIRA, D. L.; WEBER, O. B.; CECON, P. R. Teores de macronutrientes em mudas de aceroleira (Malpighia emarginata DC.) em função da composição do substrato. Ciência e Agrotecnologia, Lavras, v. 30, n. 6, p. 1110 - 1115, 2006.

LOPES, A. S.; GUIDOLIN, J. A. Interpretação de análise de solos: conceitos e aplicações. ANDA, São Paulo, SP. Boletim Técnico, n. 2, 1989.

LORENZI, H. Árvores brasileiras: manual de identificação e cultivo de plantas arbóreas nativas do Brasil. Nova Odessa, SP. 5. ed. Editora Plantarum, 2008, v. 1, 384 p.

LUCAS, M. A. K.; SAMPAIO, N. V.; KOHN, E. T.; SOARES, P. F.; SAMPAIO, T. G. Avaliação de diferentes composições de substratos para a aclimatação de mudas de morangueiro (Fragaria x ananassa Duch.). Ciênca Rural, Santa Maria, v. 8, n. 1, p. 16 - 23, 2002.

MASON, E. G. A model of the juvenile growth and survival of Pinus radiata D. Don - Adding the effects of initial seedling diameter and plant handling. New Forests, West Lafayette - USA, v. 22, n. 1, p. 133 158, 2001.

MEDEIROS, A. C. de S. Aspectos de dormência em sementes de espécies arbóreas. Embrapa Florestas. Circular técnica, v. 55, 2001.

MELO, A. S.; BRITO, M. E. B.; GOIS, M. P. P.; BARRETO, M. C. V.; VIEGAS, P. R. A.; HOLANDA, F. S. R. Efeito de substratos orgânicos organominerais na formação de mudas de maracujazeiro (Passiflora edulis). Revista Científica Rural, Bagé, RS, v. 8, n. 2, p. 116 - 121, 2003. 
MINAMI, K.; PUCHALA, B. Produção de mudas de hortaliças de alta qualidade. Horticultura Brasileira, Vitória da Conquista, Ba, v. 18, p. 162 - 163, 2000. Suplemento.

NAVARRO R.; VILLAR-SALVADOR, P.; DEL CAMPO, A. Morfologia y establecimiento de los plantones. In: CORTINA, J.; PEÑUELAS, J. L.; PUÉRTOLAS, J.; SAVÉ, J.; VILAGROSA, A. (Eds). Calidad de plantações florestais para la restauración em degrados ambimentos mediterrâneos: Estado actual de conocimientos. Organismo Autónomo de Parques Nacionales, Ministerio de Medio Ambiente, Madrid, 2006, p. 67 - 88.

SARZI, I.; INOUE, A. M.; CARMELlO, Q. A. C. Produção de mudas de angico-vermelho (Anadenanthera macrocarpa (Benth.) Brenan) em substrato à base de casca de pinus compostada, variando as soluções de fertirrigação. Disponível em <www.cnpat.embrapa.br/viensub/Trab_PDF/ sub_1.pdf $>$. Acesso em: 15/03/2010.

SCHUMACHER, M. V.; CECONI, D. E.; SANTANA, C. A. Influência de diferentes doses de fósforo no crescimento de mudas de angico-vermelho (Parapiptadenia rigida (Bentham) Brenan). Revista Árvore, Viçosa, v. 28, n. 1, p. 149 - 155, 2004.

SOUZA, P. V.; CARNIEL, E.; SCHMITZ, J. A. K.; SILVEIRA, S. V. Substratos e fungos micorrízicos arbusculares no desenvolvimento vegetativo de Citrange troyer. Agropecuária Catarinense, Florianópolis, v. 16, n. 3, p. 84 - 88, 2003.

TAIZ, L.; ZEIGEL, E. Fisiologia Vegetal. 4. ed. Porto Alegre: Armed, 2009. 820 p.

TRINDADE, A. V.; MUCHOVEJ, R. M. C.; NEVES, J. C. L.; BARROS, N. F. Crescimento e nutrição de mudas de Eucaliptus grandis em resposta a composto orgânico ou adubação mineral. Revista Ceres, Viçosa, v. 48, n. 276, p. 181 - 194, 2001. 
FLORESTA, Curitiba, PR, v. 44, n. 2, p. 303 - 312, abr. / jun. 2014.

Uliana, M. B. et al. 